\title{
Preoperative platelet-to-lymphocyte ratio is a predictor of prognosis in patients with ampullary carcinoma
}

\author{
Demirci NS ${ }^{1}$, Ozdemir NY², Erdem GU ${ }^{1}$, Bozkaya $\mathrm{Y}^{1}$, Yazici $\mathrm{O}^{1}$, Zengin $\mathrm{N}^{2}$ \\ Ankara Numune Training and Research Hospital, Dept of Medical Oncology, Ankara, Turkey. \\ drserkannebi@yahoo.com
}

\begin{abstract}
AIM: To emphasize the significance of the platelet-to-lymphocyte ratio (PLR) in estimating the postoperative prognosis or survival measures in patients with carcinoma of the ampulla of Vater.

METHODS: We retrospectively reviewed 82 patients, who underwent pancreaticoduodenectomy for ampullary carcinoma between July 2001 and April 2014. We investigated the predictive significance of the preoperative PLR for disease-free survival (DFS) or overall survival (OS). The possible correlations between the PLR and clinical or pathological features were also evaluated.

RESULTS: The 5-year DFS and OS rates of the patients with carcinoma of the ampulla of Vater after pancreaticoduodenectomy were $51 \%$ and $64 \%$, respectively. Multivariate analysis revealed a significantly worse OS in patients with a PLR $\geq 212$ [hazard ratio (HR): 3.446; 95\% confidence interval $(\mathrm{Cl}): 1.4-8.43 ; \mathrm{p}=0.007$ ], lymphovascular invasion (HR: 2.973; 95\% Cl: 1.25-7.03; $p=0.013$ ), or pathological stage pT3/4 (HR: $2.761 ; 95 \%$ $\mathrm{Cl}: 1-7.1 ; p=0.035)$. Similarly, DFS was significantly worse in patients with lymphovascular invasion (HR: 2.24; $95 \% \mathrm{Cl}: 1.1-4.56 ; p=0.025)$ or stage pT3/4 (HR: 2.243; 95\% Cl, 1.03-4.84; $p=0.04$ ).

CONCLUSION: The preoperative PLR shows a predictive significance for the prognosis of postoperative patients with carcinoma of the ampulla of Vater. We suggest that because of its predictive value, the PLR can be used in the development of further approaches to monitor and manage patients with poor prognosis Tab. 4, Fig. 1, Ref. 45). Text in PDF www.elis.sk.

KEY WORDS: reoperative platelet-to-lymphocyte ratio, predictor of prognosis, ampullary carcinoma.
\end{abstract}

\begin{abstract}
Abbreviations: DFS - Disease-free survival, LVI - Lymphovascular invasion, OS - Overall survival, $\mathrm{N}$ - Regional nodal metastasis, PLR - Platelet-to lymphocyte ratio, PNI - Perineural invasion, $\mathrm{SM}$ - Surgical margin, T stage - Tumour stage
\end{abstract}

\section{Introduction}

Ampullary adenocarcinomas are exceedingly rare, accounting for only $0.2-0.5 \%$ of all gastrointestinal malignancies and approximately $6 \%$ of periampullary tumours (1). The development of ampullary adenocarcinomas has shown an increasing trend (2). In addition to ampullary adenocarcinomas, other members of the periampullary tumour family include distal cholangiocarcinoma and pancreatic or duodenal adenocarcinoma. Ampullary adenocarcinomas have the most favourable prognosis compared to other periampullary tumours. It is difficult to distinguish ampullary adenocarcinomas from other members of the periampullary tumour family preoperatively. The 5-year survival rate after resection of ampullary carcinomas ranges from $30 \%$ to $70 \%$ (3-6). At the

${ }^{1}$ Ankara Numune Training and Research Hospital, Department of Medical Oncology, Ankara, Turkey, and ${ }^{2}$ Yildirim Beyazit University Faculty of Medicine, Department of Medical Oncology, Ankara, Turkey

Address for correspondence: N.S. Demirci, Ankara Numune Training and Research Hospital, Dept of Medical Oncology, 06100 Altindag, Ankara, Turkey.

Phone: +903125084600 , Fax: +903125084914 time of diagnosis, $80 \%$ of patients are eligible for resection, but approximately half of the cases recur $(7,8)$. This high rate of recurrence emphasizes the importance of seeking prognostic markers for surgical resection.

Various clinical or pathological features have been used previously to predict the postoperative prognosis of the patients with carcinoma of the ampulla of Vater, such as T stage, positive surgical margins, lymph node involvement, perineural invasion, lymphovascular invasion, histological subtype, tumour grade, and evidence of jaundice (9-13).

It was previously reported that numerous inflammatory markers, such as: the serum albumin level, C-reactive protein level, neutrophil-to-lymphocyte ratio, platelet-to-lymphocyte ratio (PLR), and modified Glasgow prognostic score, have a prognostic significance in various malignancies (14-19).

The aim of this study was to determine whether the preoperative PLR has a prognostic significance in patients undergoing ampullary adenocarcinoma resection. Additionally, we evaluated the possible association between the PLR and the clinical or pathological features of the patients.

\section{Patients and methods}

From the retrospectively reviewed database of Ankara Numune Training and Research Hospital, Department of Medical Oncology, we recruited 82 patients with histologically proven 
non-metastatic ampullary carcinoma, who underwent curative pancreaticoduodenectomy, including R0 or R1 resection, between July 2001 and May 2014.

All the patients were over 18 years of age, and some had undergone adjuvant therapies. Patients with metastatic disease at the time of diagnosis (thus not eligible for surgical intervention), those, who were medically inoperable by other means, those previously treated for another primary malignancy, and those who, were pregnant were excluded from the study.

Preoperative blood counts were measured routinely in venous blood samples from all the patients. The PLR was then calculated as the platelet count divided by the lymphocyte count.

Initially, the association between clinicopathological parameters and disease-free (DFS) or overall survival (OS) rate following pancreaticoduodenectomy was investigated using univariate and multivariate analyses. Age, sex, pathological stage of the tumour (pT stage), evidence of regional lymph node metastasis, lymphovascular invasion, perineural invasion, surgical margin positivity, whether adjuvant therapy was used, postoperative Eastern Cooperative Oncology Group (ECOG) performance score, and the PLR were the parameters evaluated in the analyses. The cut-off PLR value was determined as the median PLR: 212. Recurrence of ampullary carcinoma is defined as a newly formed local or distant metastatic tumour evident in imaging studies such as: ultrasonography, magnetic resonance imaging, or computed tomography, during follow-up. This retrospective review was initially approved by the Ethical Committee of Ankara Numune Training and Research Hospital.

\section{Statistical analysis}

$\chi^{2}$ tests were used for comparative analysis of the categorical data. The Statistical Package for the Social Sciences, version 18.0 for Windows (SPSS Inc., Chicago, IL, USA) was used for all statistical analyses. P-values less than 0.05 were deemed to indicate a statistical significance. Descriptive statistics were reported as percentages and medians. Survival analysis was performed using the Kaplan-Meier method. Variables with a $p<0.1$ on univariate analysis were further evaluated by Cox regression analysis using backward selection to determine independent predictors of survival. DFS was defined as the interval from the first day of the surgery to the date of initial recurrence or death due to any cause, whichever occurred first. OS was defined as the interval from the first day of the surgery to the date of death due to any cause or the last follow-up.

\section{Results}

Eighty-two patients were enrolled in this study, and the patient's characteristics are shown in Table 1. The median age of the population was 63 years (range, $37-83$ years), and 48 of the patients were males (58.5\%). Of the 82 patients, $43.9 \%$ were stage pT1/2 and $56.1 \%$ pT3/4. Metastasis to the regional lymph nodes was evident in $41.5 \%$ of the patients. Seven patients (8.5\%) had microscopically positive surgical margins. Adjuvant treatment was administered in 54 patients $(65.9 \%)$. Lymphovascular invasion (LVI) was evident in $34.1 \%$ of the patients and perineural invasion
Tab. 1. Patient's characteristics.

\begin{tabular}{|c|c|}
\hline Characteristics & No of patients, $n=82(\%)$ \\
\hline \multicolumn{2}{|l|}{ Age, years } \\
\hline Median & 63 \\
\hline Range & $37-83$ \\
\hline$<65$ & $47(57.3)$ \\
\hline$\geq 65$ & $35(42.7)$ \\
\hline \multicolumn{2}{|l|}{ Sex } \\
\hline Mele & $48(58.5)$ \\
\hline Female & $34(41.5)$ \\
\hline \multicolumn{2}{|l|}{ PLR } \\
\hline Median & 212 \\
\hline Range & $79.5-614.2$ \\
\hline Low & $41(50)$ \\
\hline High & $41(50)$ \\
\hline \multicolumn{2}{|l|}{ Jaundice } \\
\hline Yes & $48(58.5)$ \\
\hline No & $34(41.5)$ \\
\hline \multicolumn{2}{|c|}{ ECOG performance status } \\
\hline $0-1$ & $60(73.2)$ \\
\hline $2-3$ & $22(26.8)$ \\
\hline \multicolumn{2}{|l|}{ pT stage } \\
\hline $1-2$ & $36(43.9)$ \\
\hline $3-4$ & $46(56.1)$ \\
\hline \multicolumn{2}{|c|}{ Regional Lymph Node Metastasis } \\
\hline Positive & $34(41.5)$ \\
\hline Negative & $48(58.5)$ \\
\hline \multicolumn{2}{|c|}{ Lymphovascular invasion } \\
\hline Yes & $28(34.1)$ \\
\hline No & $46(56.1)$ \\
\hline \multicolumn{2}{|c|}{ Perineural invasion } \\
\hline Yes & $23(28)$ \\
\hline No & $51(62.2)$ \\
\hline \multicolumn{2}{|l|}{ Surgical margin } \\
\hline Positive & $7(8.5)$ \\
\hline Negative & $75(91.5)$ \\
\hline \multicolumn{2}{|c|}{ Adjuvant treatment } \\
\hline Yes & $54(65.9)$ \\
\hline No & $28(34.1)$ \\
\hline
\end{tabular}

ECOG: Eastern cooperative oncology group, PLR: platelet-lymphocyte ratio, High PLR: PLR $\geq 212$, pT: pathological tumor stage

Tab. 2. Clinicopathological features in relation to the platelet to lymphocyte ratio.

\begin{tabular}{lccc}
\hline \multirow{2}{*}{ Features } & \multicolumn{3}{c}{ PLR } \\
\cline { 2 - 4 } & $\begin{array}{c}<212 \\
(\mathrm{n}=41)\end{array}$ & $\begin{array}{c}\geq 212 \\
(\mathrm{n}=41)\end{array}$ & $\mathrm{p}$ \\
\hline Age, years $(<65 / \geq 65)$ & $27 / 14$ & $20 / 21$ & 0.118 \\
Sex $(\mathrm{m} / \mathrm{f})$ & $22 / 19$ & $26 / 15$ & 0.370 \\
pT stage (T1-T2/T3-T4) & $18 / 23$ & $18 / 23$ & 1 \\
Regional Lymph Node Metastasis (yes/no) & $25 / 16$ & $23 / 18$ & 0.654 \\
Surgical Margin Status (positive/negative) & $5 / 36$ & $2 / 39$ & 0.236 \\
Lymphovascular invasion (yes/no) & $13 / 23$ & $15 / 23$ & 0.766 \\
Perineural invasion (yes/no) & $12 / 24$ & $11 / 27$ & 0.684 \\
Jaundice (yes/no) & $26 / 15$ & $22 / 19$ & 0.370 \\
ECOG performance status (0-1/3) & $32 / 9$ & $28 / 13$ & 0.319 \\
Adjuvant Treatment (yes/no) & $26 / 15$ & $28 / 13$ & 0.641
\end{tabular}

ECOG: Eastern cooperative oncology group, PLR: platelet-lymphocyte ratio, $\mathrm{pT}$ : pathological tumor stage

(PNI) in $28 \%$ of the patients. The ECOG performance status of patients was $0 / 1$ in $73.2 \%$ of the population, and the most common symptom observed was jaundice $(58.5 \%)$. 
180-186

Tab. 3. Univariate and multivariate analyses of clinicopathological features in relation to disease free survival after pancreaticoduodenectomy for carcinoma of the ampulla of Vater.

\begin{tabular}{|c|c|c|c|c|c|c|c|}
\hline \multirow{2}{*}{ Patients } & \multirow{2}{*}{$\mathrm{n}(\%)$} & \multirow{2}{*}{$\begin{array}{l}\text { 3-year Disease } \\
\text { free survival (\%) }\end{array}$} & \multirow{2}{*}{$\begin{array}{l}\text { 5-year Disease } \\
\text { free survival ( } \%)\end{array}$} & \multirow{2}{*}{$\begin{array}{l}\text { 10-year Disease } \\
\text { free survival (\%) }\end{array}$} & \multirow{2}{*}{$\begin{array}{c}\text { Univariate } \\
\text { analysis } \\
\text { DFS } \\
\text { P-value }\end{array}$} & \multicolumn{2}{|c|}{ Multivariate analysis } \\
\hline & & & & & & $\begin{array}{l}\text { Hazard ratio } \\
(95 \% \mathrm{CI})\end{array}$ & $\begin{array}{c}\text { DFS } \\
\text { P-value }\end{array}$ \\
\hline All patient groups & 82 & 58 & 51 & 43 & & & \\
\hline \multicolumn{8}{|l|}{ Age, years } \\
\hline$<65$ & $47(57.3)$ & 59 & 52 & 48 & \multirow{2}{*}{0.756} & & \\
\hline$\geq 65$ & $35(42.7)$ & 56 & 51 & 34 & & & \\
\hline \multicolumn{8}{|c|}{ ECOG Performance status } \\
\hline $0-1$ & $60(73.2)$ & 59 & 53 & 46 & \multirow{2}{*}{0.531} & & \\
\hline $2-3$ & $22(26.8)$ & 53 & 42 & 28 & & & \\
\hline \multicolumn{8}{|l|}{ Sex } \\
\hline Male & $48(58.5)$ & 58 & 52 & 38 & \multirow{2}{*}{0.614} & & \\
\hline Female & $34(41.5)$ & 57 & 50 & 50 & & & \\
\hline \multicolumn{8}{|l|}{ Jaundice } \\
\hline Yes & $48(58.5)$ & 51 & 45 & 34 & \multirow{2}{*}{0.301} & & \\
\hline No & $34(41.5)$ & 67 & 58 & 52 & & & \\
\hline \multicolumn{8}{|c|}{ Regional Lymph Node Metastasis } \\
\hline Positive & $34(41.5)$ & 54 & 46 & 40 & \multirow{2}{*}{0.340} & & \\
\hline Negative & $48(58.5)$ & 61 & 55 & 47 & & & \\
\hline \multicolumn{8}{|l|}{ PLR } \\
\hline Low & $41(50)$ & 68 & 65 & 46 & \multirow{2}{*}{0.027} & 1.997 & \\
\hline High & $41(50)$ & 48 & 40 & 40 & & $(0.98-4.07)$ & 0.057 \\
\hline \multicolumn{8}{|c|}{ Lymphovascular invasion } \\
\hline Yes & $28(34.1)$ & 46 & 32 & 26 & \multirow{2}{*}{0.006} & 2.249 & \\
\hline No & $46(56.1)$ & 70 & 67 & 55 & & $(1.1-4.56)$ & 0.025 \\
\hline \multicolumn{8}{|l|}{ Perineural invasion } \\
\hline Yes & $23(28)$ & 63 & 46 & - & \multirow{2}{*}{0.334} & & \\
\hline No & $51(62.2)$ & 60 & 57 & 49 & & & \\
\hline \multicolumn{8}{|l|}{ pT stage } \\
\hline $1-2$ & $36(43.9)$ & 64 & 64 & 54 & \multirow{2}{*}{0.027} & 2.243 & \\
\hline $3-4$ & $46(56.1)$ & 54 & 40 & 34 & & $(1.03-4.84)$ & 0.04 \\
\hline \multicolumn{8}{|l|}{ Surgical margin } \\
\hline Positive & $7(8.5)$ & 40 & 40 & - & \multirow{2}{*}{0.082} & & \\
\hline Negative & $75(91.5)$ & 60 & 52 & 46 & & & \\
\hline Adjuvant Treatment & & & & & & & \\
\hline Yes & $54(65.9)$ & 50 & 42 & 39 & & & \\
\hline No & $28(34.1)$ & 71 & 66 & 53 & 0.063 & & \\
\hline
\end{tabular}

ECOG: Eastern cooperative oncology group, PLR: platelet-lymphocyte ratio, High PLR: PLR $\geq 212$, pT: pathological tumor stage

The median PLR was 212 (range, 79.5-614.2). Patients with a preoperative PLR $\geq 212$ represented $50 \%$ of the whole population. No significant associations were evident between the PLR and any of the clinicopathological parameters (Tab. 2).

The median follow- up from the date of the first diagnosis was 42.4 months (range, 1.68-164 months). The 5-year DFS and OS rates of the patients with an indication of ampullary carcinoma following pancreaticoduodenectomy were $51 \%$ and $64 \%$, respectively (Tabs 3 and 4).

On univariate analysis, the factors with a potential prognostic value for DFS and OS were investigated. These parameters were age, sex, ECOG performance status, evidence of jaundice, $\mathrm{pT}$ stage, regional lymph node involvement, LVI, PNI, surgical margin positivity, history of adjuvant treatment, and the PLR. DFS was found to be significantly worse in the patients with a high PLR $(p=0.027)$, LVI $(p=0.006)$, or stage pT3/4 $(p=0.027)($ Tab. 3$)$.
On multivariate analysis, LVI (hazard ratio (HR): 2.249; 95\% confidence interval $[\mathrm{CI}]: 1.1-4.56 ; \mathrm{p}=0.025)$ and $\mathrm{pT} 3 / 4(\mathrm{HR}$ : 2.243; 95\% CI: $1.03-4.84 ; \mathrm{p}=0.04)$ remained independent and significant predictors of a poor DFS. In addition, a PLR $\geq 212$ (HR: 1.99; 95\% CI: 0.98-4.07; $\mathrm{p}=0.057$, figure-1a) also tended to be associated with a poor DFS. On the other hand, DFS was not associated with age, sex, preoperative ECOG score, preoperative evidence of jaundice, T stage, PNI, LVI, regional lymph node metastasis, surgical margin positivity, or adjuvant therapy (Tab. 3).

Table 4 summarizes the relationships between the clinicopathological features and OS rate according to the univariate and multivariate analyses. In the univariate analysis, the OS rates of the patients with a high PLR $(\mathrm{p}=0.006), \mathrm{pT} 3 / 4(\mathrm{p}=0.018)$, positive surgical margin $(p=0.015)$, LVI $(p=0.002)$, or PNI ( $p$ $=0.025)$ were significantly worse. In the multivariate analysis, pT3/4 (HR: 2.761; 95\% CI: 1.07-7.1; p = 0.035), LVI (HR: 2.973; 
Tab. 4. Univariate and multivariate analyses of clinicopathological features in relation to overall survival after pancreaticoduodenectomy for carcinoma of the ampulla of Vater.

\begin{tabular}{|c|c|c|c|c|c|c|c|}
\hline \multirow{2}{*}{ Patients } & \multirow{2}{*}{$\mathrm{n}(\%)$} & \multirow{2}{*}{$\begin{array}{c}\text { 3-year Overall } \\
\text { survival }(\%)\end{array}$} & \multirow{2}{*}{$\begin{array}{c}\text { 5-year Overall } \\
\text { survival (\%) }\end{array}$} & \multirow{2}{*}{$\begin{array}{c}\text { 10-year Overall } \\
\text { survival }(\%)\end{array}$} & \multirow{2}{*}{$\begin{array}{c}\begin{array}{c}\text { Univariate } \\
\text { analysis }\end{array} \\
\begin{array}{c}\text { OS } \\
\text { P-value }\end{array}\end{array}$} & \multicolumn{2}{|c|}{ Multivariate analysis } \\
\hline & & & & & & $\begin{array}{l}\text { Hazard ratio } \\
(95 \% \mathrm{CI})\end{array}$ & $\begin{array}{c}\text { OS } \\
\text { P-value }\end{array}$ \\
\hline All patient groups & 82 & 75 & 64 & 53 & & & \\
\hline \multicolumn{8}{|l|}{ Age, years } \\
\hline$<65$ & $47(57.3)$ & 80 & 71 & 62 & \multirow{2}{*}{0.156} & & \\
\hline$\geq 65$ & $35(42.7)$ & 68 & 53 & 35 & & & \\
\hline \multicolumn{8}{|c|}{ ECOG Performance status } \\
\hline $0-1$ & $60(73.2)$ & 75 & 68 & 57 & \multirow{2}{*}{0.317} & & \\
\hline $2-3$ & $22(26.8)$ & 75 & 46 & 34 & & & \\
\hline \multicolumn{8}{|l|}{ Sex } \\
\hline Male & $48(58.5)$ & 73 & 70 & 57 & \multirow{2}{*}{0.696} & & \\
\hline Female & $34(41.5)$ & 78 & 58 & 52 & & & \\
\hline \multicolumn{8}{|l|}{ Jaundice } \\
\hline Yes & $48(58.5)$ & 73 & 60 & 51 & \multirow{2}{*}{0.723} & & \\
\hline No & $34(41.5)$ & 78 & 70 & 56 & & & \\
\hline \multicolumn{8}{|c|}{ Regional Lymph Node Metastasis } \\
\hline Positive & $34(41.5)$ & 67 & 54 & 43 & \multirow{2}{*}{0.064} & & \\
\hline Negative & $48(58.5)$ & 80 & 71 & 64 & & & \\
\hline \multicolumn{8}{|l|}{ PLR } \\
\hline Low & $41(50)$ & 92 & 79 & 61 & \multirow{2}{*}{0.006} & 3.446 & 0007 \\
\hline High & $41(50)$ & 57 & 47 & 47 & & $(1.4-8.43)$ & 0.007 \\
\hline \multicolumn{8}{|c|}{ Lymphovascular invasion } \\
\hline Yes & $28(34.1)$ & 66 & 47 & 34 & \multirow{2}{*}{0.002} & 2.973 & \\
\hline No & $46(56.1)$ & 84 & 81 & 71 & & $(1.25-7.03)$ & 0.013 \\
\hline \multicolumn{8}{|l|}{ Perineural invasion } \\
\hline Yes & $23(28)$ & 67 & 49 & 41 & \multirow{2}{*}{0.025} & & \\
\hline No & $51(62.2)$ & 81 & 75 & 63 & & & \\
\hline \multicolumn{8}{|l|}{ T stage } \\
\hline $1-2$ & $36(43.9)$ & 85 & 78 & 64 & \multirow{2}{*}{0.018} & $2.761 ; 95 \% \mathrm{CI}$ & 0035 \\
\hline $3-4$ & $46(56.1)$ & 67 & 52 & 45 & & $1.07-7.1$ & 0.035 \\
\hline \multicolumn{8}{|l|}{ Surgical margin } \\
\hline Positive & $7(8.5)$ & 54 & 36 & - & \multirow{2}{*}{0.015} & & \\
\hline Negative & $75(91.5)$ & 77 & 64 & 58 & & & \\
\hline Adjuvant Treatmen & & & & & & & \\
\hline Yes & $54(65.9)$ & 66 & 54 & 64 & 0,057 & & \\
\hline No & $28(34.1)$ & 89 & 79 & 51 & 0.051 & & \\
\hline
\end{tabular}

ECOG: Eastern cooperative oncology group, PLR: platelet-lymphocyte ratio, High PLR: PLR $\geq 212$, pT: pathological tumor stage

95\% CI: $1.25-7.03 ; \mathrm{p}=0.013$ ), and a high PLR (HR: 3.446; 95\% CI: $1.4-8.43 ; \mathrm{p}=0.007$ ) (Fig. 1) remained independent and significant prognostic predictors of poor OS. On the other hand, OS was not associated with age, sex, preoperative ECOG score, evidence of jaundice, PNI, regional lymph node metastasis, or adjuvant therapy.

\section{Discussion}

We found the PLR to be predictive of the prognosis of the patients after resection of ampullary carcinoma. To our knowledge, this is the most comprehensive study, involving a large number of patients, to evaluate the predictive utility of PLR for the postoperative prognosis of the patients with ampullary carcinoma.

Today, although still unclear, systemic inflammatory response seems to play an important role in tumour initiation, invasion, or progression (20). In numerous studies, it was previously reported that the microenvironment of the tumour is important for tumour progression as well as survival (21).

Evaluation of numerous immune mediators, such as interleukin-1 (IL-1), IL-3, and IL-6, showed that systemic inflammation increased the number of circulating thrombocytes and the megakaryocyte burden $(22,23)$. Transforming growth factor beta, IL10 , and other inhibitory cytokines secreted by inflammatory cells located in the tumour microenvironment, decrease the numbers of tumour-infiltrating and -circulating lymphocytes. Thus, the inflammatory response is disturbed in malignancy (24).

Recently, various inflammatory markers that are readily accessible and cost effective were identified and utilized to evaluate the prognosis of several malignancies (25-27). As mentioned previously, it was reported that inflammatory factors such as: albumin, $\mathrm{C}$-reactive protein, and the PLR have a prognostic significance in 

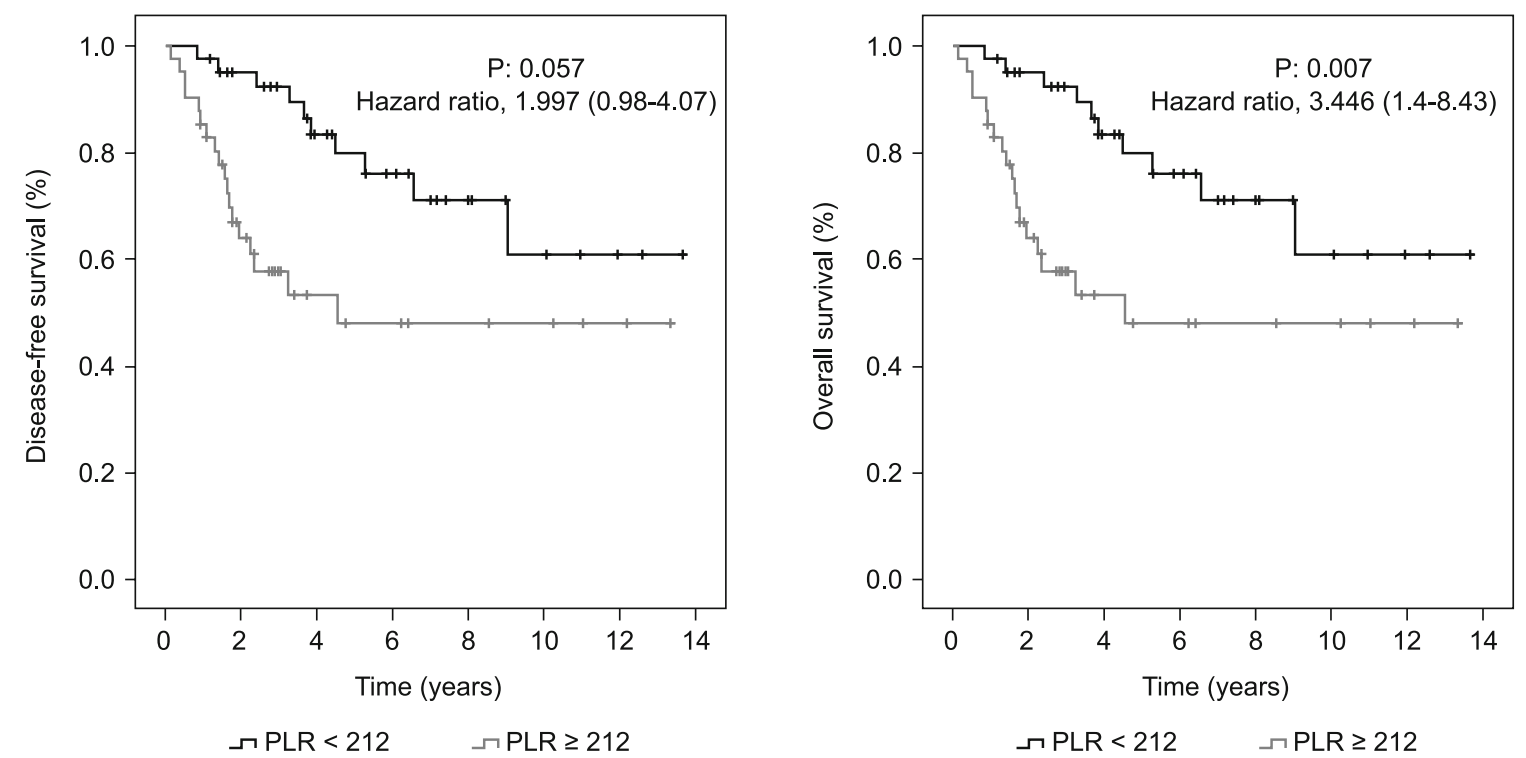

Fig. 1. Kaplan-Meier curves for disease-free (a) and overall (b) survival after pancreaticoduodenectomy.

numerous types of malignancies $(28,29)$. A high PLR has been associated with poor prognosis in numerous types of malignancies, namely breast, gastric, colorectal, ovary, pancreas, hepatocellular, and lung cancers (30-36). Unfortunately, the underlying mechanism is not yet clear. Platelets may cause expansion, as well as progression, of the tumour, because they stimulate angiogenesis via vascular endothelial growth factor production (37). Besides vascular endothelial growth factor, platelets produce several other growth factors, including transforming growth factor beta and platelet-derived endothelial cell growth factor $(38,39)$, that contribute to tumour growth (40). Platelet-derived pro-angiogenic mediators secreted during adhesion and aggregation of platelets also play significant roles in tumour expansion or potentially metastasis (41). According to this previous knowledge, the levels of thrombocytosis and lymphopenia act in conjunction with the level of systemic inflammation and, therefore, may reflect the PLR. Thrombocytosis and lymphocytopenia in peripheral blood increase the PLR. In more conceptual terms, thrombocytosis and lymphopenia are already considered when monitoring cancer patients, because they have been correlated with poor prognosis in many malignancies (42-45).

To our knowledge, only one previous study, by Smith et al. including 75 patients, has investigated the association between the PLR and the survival of resected ampullary carcinoma patients (19). In that study, the median follow-up of 22.5 months was conducted, a cut-off PLR of 160 was used. The PLR was determined in 65 patients, of whom 26 had a PLR $>160$. The OS rates were significantly poor in patients with a high PLR (78.7 vs. 16.6 months, respectively; $\mathrm{p}<0.001$ ), positive lymph nodes (47.8 vs 14.4 months; $\mathrm{p}=$ $0.001)$, tumour diameter $>2 \mathrm{~cm}$ (44.3 vs 16.6 months; $\mathrm{p}=0.036)$, and positive surgical margins (78.7 vs 11.5 months; $p<0.001$ ).
Similarly, we found that positive surgical margins, lymph node involvement, and evidence of PNI were positively correlated with a worse OS in this study. Additionally, we previously reported that advanced T stage (HR: 2.761; 95\% CI: $1-7.1 ; \mathrm{p}=0.035$ ), LVI (HR: 2.973 ; 95\% CI: $1.25-7.03 ; \mathrm{p}=0.013$ ), and a high PLR (HR: 3.446 ; 95\% CI: $1.4-8.43 ; \mathrm{p}=0.007$ ) were independently and significantly correlated with a worse OS. LVI and T stage are predictors of a poor DFS in the patients with ampullary carcinomas (13). As expected, patients with a positive LVI and advanced $\mathrm{T}$ stage had worse DFS rates in our study.

Although not significant, patients in our cohort, who previously received adjuvant therapy, had lower OS rates. The fact that these patients had an initial clinical or pathological diagnosis suggestive of a poor prognosis might be the reason for this.

As previously emphasized, various clinicopathological features, including $\mathrm{T}$ stage, positive surgical margins, lymph node involvement, PNI, LVI, histological subtype, tumour grade, and evidence of jaundice, have predictive value for the prognosis of patients with carcinoma of the ampulla of Vater (9-13). Although correlations between the PLR and clinical or pathological features in various types of malignancies were reported previously, we did not detect such correlations (Tab. 2).

In our study, a high PLR was significantly correlated with OS in the univariate and multivariate analyses. Regarding DFS, there was a significant correlation between DFS and the PLR in the univariate analysis, but not statistically significant in the multivariate analysis.

The most important limitation of this study was its retrospective design. Additionally, certain factors that potentially affect prognosis (e.g., tumour grade, histological subtype, and the adjuvant therapy protocol) were not evaluated. However, this is the 
most comprehensive study to evaluate the potential predictive value of the PLR for the postoperative prognosis and survival of patients with ampullary carcinoma.

\section{Conclusion}

Here, we suggest that the preoperative PLR may be predictive of survival in patients with ampullary carcinoma. Because it is a cost-effective and readily accessible measure, the PLR is a useful marker in almost all cases. By predicting the patients with a poor prognosis beforehand, the PLR may help with future efforts to monitor and manage patients with ampullary carcinoma.

\section{References}

1. Rosenberg R, Friederichs J, Schuster T, Gertler R, Maak M, Becker $\mathbf{K}$ et al. Prognosis of patients with colorectal cancer is associated with lymph node ratio: a single-center analysis of 3,026 patients over a 25 -year time period. Ann Surg 2008; 248 (6): 968-978.

2. Albores-Saavedra J, Schwartz AM, Batich K, Henson DE. Cancers of the ampulla of vater: demographics, morphology, and survival based on 5,625 cases from the SEER program. J Surg Oncol 2009; 100 (7): 598-605.

3. Bettschart V, Rahman MQ, Engelken FJ, Madhavan KK, Parks RW, Garden OJ. Presentation, treatment and outcome in patients with ampullary tumours. Brit J Surg 2004; 91 (12): 1600-1607.

4. Colussi O, Voron T, Pozet A, Hammel P, Sauvanet A, Bachet JB et al. Prognostic score for recurrence after Whipple's pancreaticoduodenectomy for ampullary carcinomas; results of an AGEO retrospective multicenter cohort. Eur J Surg Oncol 2015; 41 (4): 520-526.

5. Miyakawa S, Ishihara S, Horiguchi A, Takada T, Miyazaki M, Nagakawa T. Biliary tract cancer treatment: 5,584 results from the Biliary Tract Cancer Statistics Registry from 1998 to 2004 in Japan. J Hepato Biliar Pancreat Surg 2009; 16 (1): 1-7.

6. Morris-Stiff G, Alabraba E, Tan YM, Shapey I, Bhati C, Tanniere $\mathbf{P}$ et al. Assessment of survival advantage in ampullary carcinoma in relation to tumour biology and morphology. European journal of surgical oncology : the journal of the European Society of Surgical Oncology and the Brit Ass Surg Oncol 2009; 35 (7): 746-750.

7. Beger HG, Treitschke F, Gansauge F, Harada N, Hiki N, Mattfeldt T. Tumor of the ampulla of Vater: experience with local or radical resection in 171 consecutively treated patients. Arch Surg 1999; 134 (5): 526-532.

8. Sellner FJ, Riegler FM, Machacek E. Implications of histological grade of tumour for the prognosis of radically resected periampullary adenocarcinoma. Eur J Surg Acta Chir 1999; 165 (9): 865-870.

9. Chen JW, Bhandari M, Astill DS, Wilson TG, Kow L, Brooke-Smith $\mathbf{M}$ et al. Predicting patient survival after pancreaticoduodenectomy for malignancy: histopathological criteria based on perineural infiltration and lymphovascular invasion. HPB 2010; 12 (2): 101-108.

10. Lowe MC, Coban I, Adsay NV, Sarmiento JM, Chu CK, Staley CA et al. Important prognostic factors in adenocarcinoma of the ampulla of Vater. Amer Surg 2009; 75 (9): 754-760.

11. Neoptolemos JP, Moore MJ, Cox TF, Valle JW, Palmer DH, McDonald AC et al. Effect of adjuvant chemotherapy with fluorouracil plus folinic acid or gemcitabine vs observation on survival in patients with resected periampullary adenocarcinoma: the ESPAC-3 periampullary cancer randomized trial. JAMA 2012; 308 (2): 147-156.
12. Pomianowska E, Westgaard A, Mathisen O, Clausen OP, Gladhaug IP. Prognostic relevance of number and ratio of metastatic lymph nodes in resected pancreatic, ampullary, and distal bile duct carcinomas. Ann Surg Oncol 2013; 20 (1): 233-241.

13. Winter JM, Cameron JL, Olino K, Herman JM, de Jong MC, Hruban RH et al. Clinicopathologic analysis of ampullary neoplasms in 450 patients: implications for surgical strategy and long-term prognosis. J Gastrointest Sugr 2010; 14 (2): 379-387.

14. Grivennikov SI, Greten FR, Karin M. Immunity, inflammation, and cancer. Cell 2010; 140 (6): 883-899.

15. Halazun KJ, Aldoori A, Malik HZ, Al-Mukhtar A, Prasad KR, Toogood GJ et al. Elevated preoperative neutrophil to lymphocyte ratio predicts survival following hepatic resection for colorectal liver metastases. Eur J Surg Oncol 2008; 34 (1): 55-60.

16. Han S, Liu Y, Li Q, Li Z, Hou H, Wu A. Pre-treatment neutrophilto-lymphocyte ratio is associated with neutrophil and T-cell infiltration and predicts clinical outcome in patients with glioblastoma. BMC Cancer 2015; $15: 617$.

17. Haruki K, Shiba H, Horiuchi T, Shirai Y, Iwase R, Fujiwara Y et al. Neutrophil to Lymphocyte Ratio Predicts Therapeutic Outcome After Pancreaticoduodenectomy for Carcinoma of the Ampulla of Vater. Anticancer Res 2016; 36 (1): 403-408.

18. Paramanathan A, Saxena A, Morris DL. A systematic review and meta-analysis on the impact of pre-operative neutrophil lymphocyte ratio on long term outcomes after curative intent resection of solid tumours. Surg Oncol 2014; 23 (1): 31-39.

19. Smith RA, Ghaneh P, Sutton R, Raraty M, Campbell F, Neoptolemos JP. Prognosis of resected ampullary adenocarcinoma by preoperative serum CA19-9 levels and platelet-lymphocyte ratio. J Gastroint Surg 2008; 12 (8): 1422-1428.

20. Grange JM, Krone B, Mastrangelo G. Infection, inflammation and cancer. Internat J Cancer 2011; 128 (9): 2240-2241.

21. Mantovani A, Romero P, Palucka AK, Marincola FM. Tumour immunity: effector response to tumour and role of the microenvironment. Lancet 2008; 371 (9614): 771-783.

22. Alexandrakis MG, Passam FH, Moschandrea IA, Christophoridou AV, Pappa CA, Coulocheri SA et al. Levels of serum cytokines and acute phase proteins in patients with essential and cancer-related thrombocytosis. Amer J Clin Oncol 2003; 26 (2): 135-140.

23. Klinger MH, Jelkmann W. Role of blood platelets in infection and inflammation. J Interferon Cytokine Res 2002; 22 (9): 913-922.

24. Salazar-Onfray F, Lopez MN, Mendoza-Naranjo A. Paradoxical effects of cytokines in tumor immune surveillance and tumor immune escape. Cytokine Growth Factor Rev 2007; 18 (1-2): 171-182.

25. Chan AW, Chan SL, Wong GL, Wong VW, Chong CC, Lai PB et al. Prognostic Nutritional Index (PNI) Predicts Tumor Recurrence of Very Early/Early Stage Hepatocellular Carcinoma After Surgical Resection. Ann Surg Oncol 2015; 22 (13): 4138-4148.

26. Goh BK, Chok AY, Allen JC, Jr., Quek R, Teo MC, Chow PK et al. Blood neutrophil-to-lymphocyte and platelet-to-lymphocyte ratios are independent prognostic factors for surgically resected gastrointestinal stromal tumors. Surgery 2016; 159 (4): 1146-1156.

27. Goh BK, Tan DM, Chan CY, Lee SY, Lee VT, Thng CH et al. Are preoperative blood neutrophil-to-lymphocyte and platelet-to-lymphocyte ratios useful in predicting malignancy in surgically-treated mucin-producing pancreatic cystic neoplasms? J Surg Oncol 2015; 112 (4): 366-371. 
180-186

28. Malietzis G, Giacometti M, Askari A, Nachiappan S, Kennedy RH, Faiz OD et al. A preoperative neutrophil to lymphocyte ratio of 3 predicts disease-free survival after curative elective colorectal cancer surgery. Ann Surg 2014; 260 (2): 287-292.

29. McMillan DC. An inflammation-based prognostic score and its role in the nutrition-based management of patients with cancer. Proc Nutrit Soc 2008; 67 (3): 257-262.

30. Asher V, Lee J, Innamaa A, Bali A. Preoperative platelet lymphocyte ratio as an independent prognostic marker in ovarian cancer. Clin Translat Oncol 2011; 13 (7): 499-503.

31. Diem S, Schmid S, Krapf M, Flatz L, Born D, Jochum W et al. Neutrophil-to-Lymphocyte ratio (NLR) and Platelet-to-Lymphocyte ratio (PLR) as prognostic markers in patients with non-small cell lung cancer (NSCLC) treated with nivolumab. Lung Cancer 2017; 111: 176-181.

32. Goh BK, Kam JH, Lee SY, Chan CY, Allen JC, Jeyaraj P et al. Significance of neutrophil-to-lymphocyte ratio, platelet-to-lymphocyte ratio and prognostic nutrition index as preoperative predictors of early mortality after liver resection for huge $(>/=10 \mathrm{~cm})$ hepatocellular carcinoma. J Surg Oncol 2016; 113 (6): 621-627.

33. He W, Yin C, Guo G, Jiang C, Wang F, Qiu H et al. Initial neutrophil lymphocyte ratio is superior to platelet lymphocyte ratio as an adverse prognostic and predictive factor in metastatic colorectal cancer. Med Oncol 2013; 30 (1): 439.

34. Krenn-Pilko S, Langsenlehner U, Thurner EM, Stojakovic T, Pichler M, Gerger A et al. The elevated preoperative platelet-to-lymphocyte ratio predicts poor prognosis in breast cancer patients. Brit J Cancer 2014; 110 (10): 2524-2530.

35. Raungkaewmanee S, Tangjitgamol S, Manusirivithaya S, Srijaipracharoen S, Thavaramara T. Platelet to lymphocyte ratio as a prognostic factor for epithelial ovarian cancer. J Gynec Oncol 2012; 23 (4): 265-273.
36. Smith RA, Bosonnet L, Raraty M, Sutton R, Neoptolemos JP, Campbell F et al. Preoperative platelet-lymphocyte ratio is an independent significant prognostic marker in resected pancreatic ductal adenocarcinoma. Amer J Surg 2009; 197 (4): 466-472.

37. Bambace NM, Holmes CE. The platelet contribution to cancer progression. J Thromb Haemost 2011; 9 (2): 237-249.

38. Heldin CH, Westermark B. Platelet-derived growth factor: mechanism of action and possible in vivo function. Cell Regul 1990; 1 (8): $555-566$.

39. Miyazono K, Yuki K, Takaku F, Wernstedt C, Kanzaki T, Olofsson A et al. Latent forms of TGF-beta: structure and biology. Ann NY Acad Sci 1990; 593: 51-58.

40. Miyazono K, Okabe T, Urabe A, Takaku F, Heldin CH. Purification and properties of an endothelial cell growth factor from human platelets. J Biol Chem 1987; 262 (9): 4098-4103.

41. Sierko E, Wojtukiewicz MZ. Platelets and angiogenesis in malignancy. Semin Thromb Hemost 2004; 30 (1): 95-108.

42. Brown KM, Domin C, Aranha GV, Yong S, Shoup M. Increased preoperative platelet count is associated with decreased survival after resection for adenocarcinoma of the pancreas. Amer J Surg 2005; 189 (3): 278-282.

43. Fogar P, Sperti C, Basso D, Sanzari MC, Greco E, Davoli C et al. Decreased total lymphocyte counts in pancreatic cancer: an index of adverse outcome. Pancreas 2006; 32 (1): 22-28.

44. Ikeda M, Furukawa H, Imamura H, Shimizu J, Ishida H, Masutani S et al. Poor prognosis associated with thrombocytosis in patients with gastric cancer. Ann Surg Oncol 2002; 9 (3): 287-291.

45. Monreal M, Fernandez-Llamazares J, Pinol M, Julian JF, Broggi M, Escola D et al. Platelet count and survival in patients with colorectal cancer - a preliminary study. Thromb Haemost 1998; 79 (5): 916-918. 